\title{
Atypical Cervical Stromal Cells Masquerading as Malignancy
}

\author{
Shraddha Avinash Kurekar*, Jayashri Popat Chaudhari, Asha Sharad Shenoy and Rachana Amit Chaturvedi \\ Department of Pathology, Seth G. S. Medical College \& KEM Hospital, Mumbai, India
}

\section{ABSTRACT}

Atypical stromal cells (ASCs) of the female genital tract are uncommon and found in various polypoid lesions of the vulva, vagina, cervix and endometrium. Although they are benign; they can be misinterpreted as a malignant. Hence it is important for a pathologist to identify the ASCs in the specimens or biopsies of lower Female genital tract and avoid over diagnosis as a malignancy. We present a case of atypical cervical stromal cells in a 45-year-old female. On microscopy, Atypical stromal cells were stellate, enlarged in size, with moderate to severely atypical hyperchromatic, multilobulated nuclei without any mitoses. Their chromatin was dense often with prominent nucleoli. This report highlights the significance of awareness about the occurrence of these cells in the female reproductive tract.

Keywords: Atypical stromal cells, Mast cells, Bizarre, Multilobed, Cervix

\section{Introduction}

Atypical stromal cells (ASCs) of the female genital tract are uncommon and found in various polypoid lesions of the vulva, vagina, cervix and endometrium. ${ }^{[1]}$ Although they are benign; they can be misinterpreted as a malignant. ${ }^{[2]}$ Hence it is important for a pathologist to identify the ASCs in the specimens or biopsies of lower Female genital tract and avoid over diagnosis as a malignancy. In this case report, we present a case of atypical cervical stromal cells in a 45-year-old female with heavy menstruation.

\section{Case Report}

A 45-year-old female presented with complaints of heavy blood loss during menstruation and prolonged menstrual cycles since six to seven months. She underwent total abdominal hysterectomy with left salpingo-oopherectomy. On gross examination, uterus measured $13 \times 10 \times 6 \mathrm{~cm}$, attached fallopian tube measured $6 \times 1.5 \mathrm{~cm}$, one cystic structure measuring $3.5 \times 2 \times 2.5 \mathrm{~cm}$ identified attached to the ovary measuring $2 \times 1.5 \times 0.4 \mathrm{~cm}$. On cut surface endometrial cavity was identified. Myometrium appeared thickened with trabeculations. Cervix showed a slightly myxoid subepithelial band. (Fig.1a). In Ovary, corpus luteum and corpus albicans were identified. On microscopy, endometrium was in proliferative phase, myometrium showed adenomyosis, cervix showed many Nabothian cysts, squamous metaplasia and many singly scattered and clusters of atypical stromal cells with many mast cells. Atypical stromal cells were stellate, enlarged in size, with moderate to severely atypical hyperchromatic, multilobulated nuclei without any mitoses. (Fig.1b,1c) Their chromatin was dense often with prominent nucleoli.
(Fig.1c) Ovary showed corpus luteal cyst. There was no evidence of malignancy in any organ.

\section{Discussion}

Atypical stromal cells were first described by Elliot in 1973 in the sub-epithelial layer of the cervix including some with bizarre nuclei. Abdul-Karim et al studied 205 cases from autopsy and hysterectomy where he found ASC in $13 \%$ cases, more common in vagina than cervix. ${ }^{[3]}$ These cells are also noted in association with lichen sclerosus, vaginal polyps, cervical prolapse, squamous cell carcinoma, endometrial polyps and adenomyosis. ${ }^{[2]}$ In our case, there was adenomyosis of myometrium, with ASCs in the cervix. There was no other cervical pathology.-

Morphology of ASCs varies from hyperchromatic mononuclear fibroblastic spindle cells to bizarre multinucleated or multilobed. Mitotic figures are absent and nucleoli are inconspicuous. ${ }^{[3]}$ This will help to differentiate these from malignant cells. As observed by Abdul et al, the connective tissue stroma was variable in density and did not appear to have any relationship with presence of ASC. However our case showed band like loose myxoid zone in the ectocervix grossly and microscopically in the ectocervix as observed by Elliot et al. ${ }^{[3]}$ These ASCs invariably shows positivity for vimentin, estrogen, androgen and progesterone receptors. They are focally positive for CD10, actin, desmin, h-caldesmon and S-100. They are negative for Cytokeratins, CD34, epithelial membrane antigen. ${ }^{[3]}$

Atypical stromal cells are suggested to develop due to a degenerative or reactive phenomenon. ${ }^{[4]}$ The origin of 


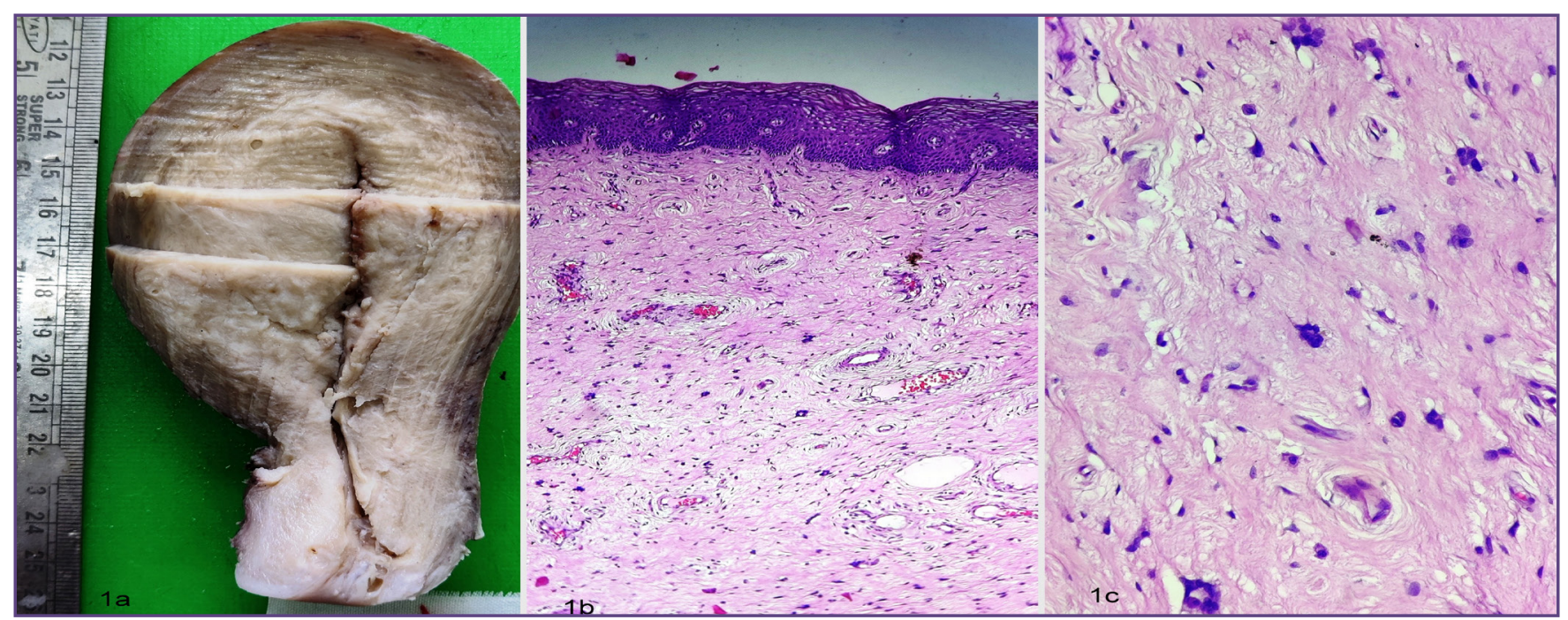

Fig. 1a: Gross cervix showing myxoid subepithelial band and nabothian cyst. 1b: Atypical cervical stromal cells and mast cells (H\& E x 100) 1c: Large stellate cells with hyperchromatic multilobated nuclei (H\&E x 400).

atypical stromal cells is still unclear and several hypothesis have been considered. ${ }^{[4]}$ Some authors believe that ASC originate from primitive stem cell population which is present in the thin myxoid subepithelial layer of lower female genital while other consider peripheral nerve sheath origin because of the presence of pseudo-inclusions, multilobation, intracellular filaments and S-100 positivity while some consider smooth muscle or endometrial stromal cell origin. ${ }^{[2]}$ Rodrigues MI et al. observed a relationship between mast cells and atypical stromal cells present in vaginal polyps and normal anus mucosa. ${ }^{[2]}$ In our case we have found ASCs in the background of mast cells which supports this hypothesis.

ASCs can be misdiagnosed as malignancy. Various differential diagnoses considered in different parts of lower genital tract and different clinical settings for ASCs in the reported literature are fibroepithelial polyps and granulation tissue polyps, Rhabdomyoma, Myofibroblastoma, smooth muscle neoplasms, aggressive Angiomyxoma, Adenosarcoma, Adenofibroma, sarcoma botryoides, blue nevus, endometrial stromal sarcoma, malignant mixed mullerian tumor, microinvasive cells from squamous cell carcinoma, endometrial stromal sarcoma, carcinosarcoma, trophoblastic lesion. ${ }^{[2]}$

\section{Conclusion}

Atypical cervical stroma cells can potentially mimic malignancy in appropriate setting. This report highlights the significance of awareness about the occurrence of these cells in the female reproductive tract.

\section{Abbreviations}

ASCs: Atypical stromal cells

\section{Acknowledgements}

None

\section{Funding \\ None}

\section{Competing Interests}

None

\section{References}

1. Monaco ML, Puzzo L, Brancato F, Torrisi A, Magro G. Endometrial atypical (bizarre) stromal cells: A potential diagnostic pitfall in biopsy. Pathol - Res Pract. 2004;200(9):625-7.

2. Rodrigues MI, Goez E, Larios KK, et al. Atypical stromal cells as a diagnostic pitfall in lesions of the lower female genital tract and uterus: a review and presentation of some unusual cases. Patol Rev Latinoam. 2009;47(2):103-107.

3. Abdul-Karim FW, Cohen RE. Atypical stromal cells of lower female genital tract. Histopathology. 1990 Sep;17(3):249-53.

4. Tai LH, Tavassoli FA. Endometrial Polyps With Atypical (Bizarre) Stromal Cells: Am J SurgPathol. 2002 Apr;26(4):505-9.

*Corresponding author:

Shraddha Avinash Kurekar, Bawalawadi hostel, B wing, Opposite voltas house, Dr Babasaheb Ambedkar road,

Chinchpokli, Mumbai- 400012, India.

Phone: +918237656321

Email: shraddhakurekar1@gmail.com

Date of Submission $\quad: 01 / 12 / 2020$

Financial or other Competing Interests: None. 